\title{
Animal Genomics and Ambivalence: A Sociology of Animal Bodies in Agricultural Biotechnology
}

\author{
RICHARD TWINE ${ }^{1}$
}

\begin{abstract}
How may emergent biotechnologies impact upon our relations with other animals? To what extent are any changes indicative of new relations between society and nature? This paper critically explores which sociological tools can contribute to an understanding of the technologisation of animal bodies. By drawing upon interview data with animal scientists I argue that such technologies are being partly shaped by broader changes in agriculture. The complexity of genomics trajectories in animal science is partly fashioned through the deligitimisation of the productivist paradigm but continue to sit in tension around particular conceptions of sustainability in farm animal production.
\end{abstract}

In spite of this deligitimisation process genomics is now being framed in the context of a new productivism (termed the livestock revolution) bound up in projected global changes in animal consumption during the first half of the $21^{\text {st }}$ century. This potentially jars against both social trends that seek to re-enchant animal life and sustainability discourses which include social and environmental contexts. Nevertheless the possibility of a new productivism is supported by various interconnected trends including the emergence of a discourse of the 'bioeconomy' and a liberal regulatory apparatus for farm animal breeding technologies. Ultimately an understanding of the possibility of emerging new bio-capitalisations on animal life should be set in a broader context of competing agricultural paradigms as well as ongoing tensions over 'naturalness' in human/animal relations.

\section{Introduction}

Much of the sociological literature speaks of contemporary Western human/animal relations as characterised by an ambivalence which came to cultural prominence during the twentieth century. ${ }^{2}$ Animal Genomics I shall argue sits productively within the nexus of this ambivalence. On the one hand we can note a historical move toward less instrumental human/animals relations; and the emergence of ethics of care which have inspired hubris challenging reflexivity within modern intensive agriculture and other areas. Yet significantly animals remain real conduits for bio-capitalisation and targets of human consumption at the outset of the $21^{\text {st }}$ century. Biotechnological elaborations of animal life, be they through genomics or bio-pharmaceuticals or, perhaps in the longer term, cloning ${ }^{3}$ or GM, extend the modernist mastery of nature, now for some more properly understood as a refashioning or 'bespoke' ${ }^{4}$ made to order nature. Whilst this may indicate an historical continuity with the modernist mastery of nature (constructed as separate to the human), transitioning now to a reality wherein nature becomes properly an externalised object of re/design, biotechnological impacts remain unclear owing to uncertainties over their social 
reception and technical viability. The ability of biotechnologies to further embed hybrid forms is partly dependent upon the continued erosion of the 'natural' in domains such as food and health. ${ }^{5}$

My focus in this paper is on animal biotechnologies in agriculture rather than medicine. However this choice of focus necessitates that I make clear a few points related to scope of coverage. I have argued elsewhere ${ }^{6}$ of the need to take into account the way in which developments in the biosciences promote a convergence between agricultural and biomedical domains but also that in terms of knowledge transfer there is a much longer history at play here. ${ }^{7}$ When trying to think through sociological explanations of animal biotechnologies it is cogent if possible to be attentive to these interconnections, newly emerging or otherwise. For example, it's important to appreciate that database information covering the sequenced genomes of both mice and the human is used routinely in comparative genomics in order to try and pinpoint gene function and economically interesting chromosomal loci for the farm animal sciences. Thus huge investments which in the main had the rationale to investigate human disease are also made useful to those working in farm animal science and investigations into animal gene function also feed back into human medical research. Recognising such interconnections is as yet under-theorised in the social science literature. Although the last ten years have seen a significant increase in research into the ethical, legal and social aspects of genetics this has been predominantly human centred in focus. To an extent this reflects the general invisibility of animals in Sociology ${ }^{8}$ as well as the failure to attribute sociological import to the place of animals and animality within the social. In the social science and bioethics of this area there is a specific division of labour between the false demarcation of 'red' (human, medical) and 'green' (environmental) biotech. In this unreflected repetition of the society/nature dualism it is rather unclear where animals are accommodated. Consequently sociologists are at the early stages of thinking through the biotechnological construction of human/animal relations and here I offer some signposts.

Ideally then an analysis would be broader than that imposed by space constraints here. For example most of the research that could be taken to underline Michael's ${ }^{9}$ claim of bespoke animals takes place in biomedicine. Thus the vast majority of animal research using genetically modified (GM) animals is in the area of creating animal models to study disease. There are a small number of research projects investigating both cloning and GM technologies for applications in agriculture. The company Aquabounty may be successful in commercialising the first GM animals (salmon) for human consumption in a few years' time, and cloned animal products for human consumption may be commercialised by $2010 .{ }^{10}$ The point here is that if one was to base an analysis solely on either agriculture or biomedicine without any reference to their interconnection, one might well come up with a particularly partial representation of the biotechnological shaping of human/animal relations. The unsurprising discrepancy in funding between the sequencing of the human and mouse genomes vis-à-vis those of 'agricultural' animals means that the latter lag someway behind. However due in part to its interest as a model for developmental biology the chicken genome sequence is complete and mapping projects for other major farm animals are well underway. These efforts are adding significant knowledge to the 
understanding of gene function and promoting the adoption of molecular solutions to particular problems in farm animal breeding.

My approach in this paper to producing an understanding of the biotechnological shaping of human/animal relations in the context of agriculture centres around two main aspects. First I am interested in transnational discourses which serve to frame the role of animal science in farm animal breeding in various ways. Of particular importance here is the emergence of the knowledge-based bioeconomy discourse generally and the prescribed role for animal science within this. I will argue that pivotal to the successful uptake of a new technology such as genomics is its own negotiation of its relationship to ideas of sustainable agriculture within the bioeconomy discourse. Here I also draw upon empirical research; a series of semistructured interviews with UK based animal scientists conducted in 2006. This debate on sustainability is also germane to that of global food paradigms and the future of animal ethics within food production. The second aspect I wish to focus upon is the actual work that animal science does upon animal bodies. Here I apply a Foucauldian analysis to the disciplinary power of animal sciences acting to break down and interrogate the efficiency of animal bodies in farm animal production. I argue that due to the taken-for-granted ethical lacunae around animal life, Foucault's analysis of biopower actually works better when applied to farm-animal animals. I also briefly consider how the arguments mapped out are positioned in relation to wider social theory terrains on the role of ambivalence in debates around modernity and postmodernity.

\section{Ambivalent animal futures in the 'bioeconomy'}

Although it is prudent to avoid being drawn into a teleological and linear view of progress where 'prior' instrumental views of nonhuman animal life have been gradually problematised, and to an extent discredited in parallel with the denaturalisation of gender and race relations, it is nevertheless clear that in the West the political status of animals has indeed emerged during the last thirty years. We can note a broad cultural interest in animal behaviour and interiority and, on the fringe, a rise in vegetarian and vegan practices of the self that announce a posthuman engagement with the world. In farm animal breeding itself animal welfare is a much more important issue and area of funded research compared to thirty years ago.

But even before we introduce a biotechnological slant on the discussion, we are already in the realm of contradiction and ambivalence. As Buller \& Morris point out, "while postmodernity has encouraged us to see the individuality and subjectivity of nonhumans as beings, modernity continues to put them on our plates as meat". ${ }^{11}$ Historically our emergent dissonance at the processes of animal production has been partly managed by the spatial sequestration of the sites of rearing, slaughter and preparation. Arguably our cultural tendency to disengage with animal ambivalence also makes it harder to bring animals into academic study and to encourage public engagement on the social and ethical aspects of farm animal breeding. If we think of biotechnological approaches to animals as at least partly re-embedding modernist values of control and mastery then it is not difficult to see why, emotionally, it may be a difficult subject for people to explore. 
In this section I want to try and explain animal biotechnology in terms of this recent history of partial animal subjectification. In fact I want to suggest that animal science is in tension and is best understood as being shaped by both 'postmodern' values as well by the 're-embedding' of modernity. ${ }^{12}$ By drawing upon semi-structured interview data carried out with animal scientists I will point to the ways in which this tension is expressed and how the productivist paradigm has been partly diluted. New molecular techniques such as animal genomics are being partly shaped by a strong discourse of sustainability in contemporary agriculture complimented - and sometimes contradicted - by their framing within the emerging idea of the bioeconomy. It is within the bioeconomy discourse and the related rejuvenation of the anatamopolitics of animal bodies to be discussed later that we can potentially point to the re-embedding of modernist values in animal science.

Although I have referred to a broader cultural ambivalence in our human/animal relations expressed through a tension between explorations of animal subjectivities and explorations of genomic control we can focus this down into the fields of animal science. Although it is tempting to say that behavioural and animal welfare science map onto the former and quantitative genetics and new molecular techniques map onto the latter this would be to simplify. For example genetics and genomics are being given a significant role in animal welfare and sustainability generally, and more critically, for some, a welfare approach to animal ethics would anyway be seen as complicit with instrumentalism. Indeed welfare has been quite successfully converted into a new value for the commercialisation and consumption of supposedly 'happier' animals. In spite of this caution the language and framing of animals within these branches of animal science can be strikingly different, pointing to the contested nature of the animal in contemporary animal sciences. I will revisit this point later. For the time being I want to show how the productivist paradigm in farm animal breeding has been partly diluted and deligitimised.

During 2006 I conducted semi-structured interviews with 22 UK-based animal scientists including those working on genetics, genomics, welfare and agricultural economics. These provided strong evidence for a turn against productivism. It is important to note that in the post-war period quantitative genetics and other efficiency measures had been very successful in adding to farm animal productive output. Although molecular techniques can be used to refine genetic selection it is not clear that greater productivity traditionally conceived as quantitative output is constructed as a societal need in the way it once was. Furthermore it would be accurate to say that social opposition to an emphasis on productivism is located around concerns over the industrialisation of farm animal production and so implies that a partial paradigm shift has occurred prior to and irrespective of biotechnological innovation. (Whilst it would be naïve to suggest that animal welfare has become the number one concern for UK meat consumers we can point to a $150 \%$ increase in organic meat sales between 2000 and $2005 .{ }^{13}$ Clearly concerns over industrialisation can also pertain to human health consequences.) What also became clear from the interviews is that further drivers of change have been the unforeseen consequences of pursuing narrow breeding goals. For example, selecting for high milk production has produced significant problems 
such as mastitis and declining fertility in cows. ${ }^{14}$ Here are some extracts from interviewees to illustrate the decline of productivism:

"I think people would be concerned if the product, if ... productivity was pushed much further, in terms of milk production or egg production. As I say to a large degree breeders are backing off of those traits and looking for robustness or longevity in milk production, longevity in egg production and certainly in terms of government funding for that sort of research has become more important"

"It's changed certainly I think quite dramatically. I would say up until the mid-1970s, a bit longer than that, the emphasis was on output amount. Then it became an issue of quality and efficiency and now there's a lot more emphasis on animal health and welfare and robustness"

"Oh yes, dramatically. Two changes I suppose. One has been the shift from research that's relevant to production agriculture to supporting developments in more fundamental biology. And the other shift, something more recently, is to say well, yes, we're interested in sustainable production agriculture but the only things we're really interested in are the impact on the environment or an impact on society which tends to be the DEFRA view, look at DEFRA's forward look, the emphasis on environment and sociological perspectives is enormous"

"I guess about 10-12 years ago I was seeking to find wider options in sheep breeding, basically in trying to get away from simply making sheep grow faster and have less fat. And it became apparent that there were a lot of issues to be addressed in terms of diseases and specifically genetic sort of disease resistance"

Given this historical and social context which also includes the emergence of sustainability as a key principal in agriculture and animal science funding, it is not surprising to see both quantitative genetics and newer molecular techniques partly orientated to this agenda. One interesting consequence of this is that breeding goals now include 'socially and environmentally important traits' alongside the traditional focus on selection for economic output. ${ }^{15}$ Molecular techniques can be used to optimise output (as in markers for growth and litter size) but also they are currently thought to be of best use for difficult to measure traits which can fit well with a deemphasis on production. These include disease resistance in animals and qualitative changes such as meat quality. Research in this area is accompanied by philosophical deliberation on breeding goals which now should be 'long term' and 'biologically, ecologically, and sociologically sound'. ${ }^{16}$ Similarly in their discussion of the role of genetic technologies (traditional and molecular) in improving sustainable farm animal production Bishop \& Woolliams also stress the importance of social, biological, environmental and economic viability. ${ }^{17}$ These represent interesting shifts where animal scientists are now compelled to think broadly and across disciplines about their work. ${ }^{18}$ I shall return to this point later. In their summation of current breeding goals Bishop \& Woolliams point out that increased product output and efficiency of 
production will continue to be important, but notably stating "within economies such as Western Europe, where output already exceeds requirements, such a breeding goal may be questioned". ${ }^{19}$ For them disease resistance and animal health now pose the greatest challenge to farm animal geneticists, pointing out that the cost of disease in the UK alone stands at $£ 1.7$ billion. Genomics has already been applied in this area and is expected to make further contributions. A further contributory factor here to the shaping of genomics is the recent controversy over genetic modification. That GM proved so contentious in the case of crops would tend to inspire the belief that it would be even more so in the case of animals. Thus genomics, which although a molecular technique, is being framed as an ethical and more publicly acceptable alternative ${ }^{20}$ offering the benefits of more precise controlled selection minus the extra step of transgenics.

Within the discourse of animal science the broadening out of genetic technologies to include social, environmental and animal welfare considerations finds expression in the idea of the 'win-win'. This refers to the idea of a selection that incorporates both productivity and post-productivist values such as animal welfare. In a way it might be seen as the perfect response to animal ambivalence, an attempt to satisfy both trends of instrumentalisation and subjectification in Western human/animal relations simultaneously. It's a notion that came up several times during the interviews as illustrated here by extracts, each from a different scientist:

"So in a way what we're doing is a win-win situation. If we breed animals that are more resistant to disease the farmers spend less time and less money on preventative treatments but also the welfare of the animals is improved as well in that they are inherently more healthy than, you know, had we picked the wrong sire".

"I think many farmers would believe that pushing for very high standards of welfare that perhaps people who are detached from animals aspire to, is going to cost a lot of money. But in fact a lot of our research on larger species at least shows that they can be winwins here. In diary cattle for instance we've shown that by expanding selection away from just milk production alone to include resistance to mastitis and lameness and to include fertility is expected to increase the economic returns as well as reduce welfare problems".

"Which has, you know, obviously some diseases are of major economic importance, and if one could make animals are basically fitter, healthier and more able to resist disease, then you're benefiting the animal, you're reducing the need to treat them with drugs and antibiotics so there's a potential downstream benefit for the human food chain. And so there's a sort of a potential for a winwin situation if you can do that effectively"

"I don't see production and welfare as being equivalent, but I don't see there being a problem with working on a project in which both production and welfare are improved. And it's certainly more likely to be taken up by industry if you can show that you have invented something that's going to improve both welfare and production and everybody wins" 
One point to make about the 'win-win' is that it is a genetic solution to welfare centred on the selection of the animal before it is born. There may not be anything inherently problematic with this. In fact one example that came up was that of animals that due to being selected for intensive environments over several generations had to now be 're-selected' if they were to cope with better welfare environments. Moreover it is no doubt dubious for the social scientist to unreflectively favour the environmental fix over the genetic fix for that must surely contain its own mistaken duality. Nevertheless problem-solving choices are set in an economic context and may serve to further particular ontological assumptions about, in this case, animals. The concern here may be that the partial geneticisation of welfare is also an instrumentalisation of welfare where aspects such as health and robustness may be seen as bound up in productivism as much as they are in welfare. Additionally they could be seen as invested in an overly biologistic account of farm animals, as was the concern of one animal welfare scientist interviewed:

"On the other hand there's also a trend, a parallel trend where it's almost like we're going backwards in time and welfare is becoming more and more an issue just of health, you know physical health. And that is partly this what we're talking about, you know its like metabolic stress because it's, because they're in the first place conceptualising animals as complex production systems and then they're talking about the health of that system. I see it as my own task and other colleagues is to counterbalance and to develop concepts that are close to the subjectivity of the animal. And to also, I mean how could you possibly talk about boredom and depression you know in a complex metabolic system? It's not going to happen is it?"

If one thinks of a major defining modernist assumption about animals as that which over biologises and denies their sociality as vital to a human/animal dualism then one could interpret this geneticisation of welfare as a re-embedding of modernity as it denies a space for the very subjectifying language that could subvert it. The idea that welfare is becoming more and more an issue of health may also speak to its co-option by a genetics-focused ethos. The re-embedding argument is stronger once one analyses the framing of the future of farm animal breeding within the transnational idea of the bioeconomy.

I will begin by tracing the formation of the bioeconomy discourse and then consider its relation to farm animal breeding. During the last 5-10 years the idea of the bioeconomy has emerged in European and global economic discourse as a concept which is intended to signify a new epoch of post-industrial capitalist accumulation. It encapsulates genomics and biotechnology generally in a narrative of progress that purports to address both challenges of Fordist economic decline as well as environmental limits to growth. Although the contribution of the bios to the economy (as well as that of peoples seen as closer to nature) has traditionally been 'backgrounded' ${ }^{21}$ here we have an explicit manifesto that puts the generative powers of biology at the centre of economic progress. 
In the European context, Europa-bio - The European Association of Bioindustries ${ }^{22}$ is taking a lead in shaping the meanings around the bioeconomy. It expresses a naturalising teleology in its idea of different epochs stating on its bioeconomy web portal:

"In the 18th and 19th Centuries, European society was transformed by the Industrial Revolution and the steam engine. This was the Age of Engineering. In the 20th Century, the developed world reaped the benefits of chemistry, which provided the materials, productive agriculture and medicines which make our lives so comfortable and safe. The whole world is now in transition from the Age of Chemistry to the Age of Biotechnology. Biotechnology will drive expansion of the global economy, increasing wealth while reducing Humankind's environmental footprint. We have the potential to be world leaders in innovation; the most dynamic region in the developing bio-based economy".

The European Commission is actively promoting this idea on a number of levels. These include the formation of new European Technology Platforms - essentially vision documents on an array of technologies over the next 25 years - and the inclusion of the bioeconomy in the new Framework 7 Programme; an Environmental Technology Action Plan (ETAP); and a Biofuels Directives and Biomass Action Plan. Yet this discourse is certainly transnational. China saw the first international conference on the bioeconomy in 2005 and the Organisation for Economic Cooperation and Development (OECD) is currently working up a policy agenda on the bioeconomy between now and 2030. The OECD defines the bioeconomy as

"the aggregate set of economic operations in a society that uses the latent value incumbent in biological products and processes to capture new growth and welfare benefits for citizens and nations....made possible by the recent and continuing surge in the scientific knowledge and technical competences that can be directed to harness biological processes for practical applications" ${ }^{\prime 23}$

Our new capacities to possibly harness biological labour, for example, through novel material hybrids or immortal stem cell lines or bio-remediation can, it is hoped, encourage the exploitation of newly 'liberated' biological value, arguably as a corrective to past technological excess or lifestyle mistakes. Cooper has offered one of the first historical accounts of the bioeconomy discourse arguing that it emerged out of 1970s debates on post-fordism and limits to growth. She posits a coming together of a notion of life as autopoiesis, as self-generative, with the emergence of debt finance - "the production of money from money" - as a key mode of economic power. ${ }^{24}$ The point is more than merely to underline the role that promissory venture capital plays in funding biotechnological start ups but that, for Cooper, there has been a significant discursive exchange between theoretical biology and neo-liberal theories of economic growth which has come to shape a bioeconomic vision. ${ }^{25}$ It is within environmental science and the ideas of ecological modernisation that Cooper locates this discursive exchange. I would also add that the emergence of bioeconomic modelling within agricultural economics should be seen as a significant influence. ${ }^{26}$ Essentially constituting an adaptive moment of post-industrial capitalism, ecological 
limits to growth are converted into valuable opportunities for capital accumulation, thus bio-remediation can clean up pollution and GM food can feed a growing global population. In one sense this is unsurprising given that the alternative would have been to properly reflect upon the ecological contradiction of positing progress in terms of continual economic growth.

Putting the spotlight on animal inflections of the bioeconomy discourse adds to the analysis and provides further contextual explanation for animal biotechnology trajectories. One of the aforementioned EU technology platforms is titled Sustainable Farm Animal Breeding and Reproduction ${ }^{27}$ and scopes out the research agenda until 2025. The TP working group is made up of leading figures in research and industry. Its 'vision for 2025' document illustrates how its ideas for this area are contextualised by the notion of the knowledge-based bioeconomy. Although there is little doubt that new molecular techniques should be developed at least as basic research (in part it argues because Europe must remain competitive within a knowledge-based bioeconomy), this is stressed with the proviso of transparency and public engagement. ${ }^{28}$ The bioeconomy language of sustainability is also to the fore here defined in terms of "The three pillars - people, planet and profit...sustainable breeding and reproduction means balancing food safety and public health, product quality, biodiversity, efficiency, environment, animal health, animal welfare in an economically viable way". ${ }^{29}$ Overall sustainability is given an economic slant and there is no mention of the several ways in which large-scale animal breeding is environmentally unsustainable. ${ }^{30}$ There are breeding options here, for example, in developing techniques for selecting animals that produce less phosphates or emit less ammonia and methane or selecting for disease-resistant animals, but it's unclear how viable or effective these could be.

Perhaps the most significant section of the TP vision paper refers to what is termed in the broader literature as the 'livestock revolution'. Global consumption of animal products is forecast to rise significantly over the next 20 years mostly due to increasing levels of consumption in developing countries. Whilst the FAO has expressed concern over rising levels of animal consumption in developing countries on the grounds of public health and environmental impact, ${ }^{31}$ the TP vision paper frames it as both a challenge and opportunity. Although it may be countered, as indicated above, that new genetic techniques are under investigation that could improve the healthiness of animal products and restrict their environmental impact, such changes, if viable, may well come too late. Thus while we have seen a partial deligitimisation of productivism in the UK context, it becomes apparent that in global terms animal breeding allied to an emergent transnational discourse of the bioeconomy provides the opportunity for a return to a productivist mode. Whereas molecular techniques in the UK and to an extent the wider Europe are being shaped by a turn against productivism, it will not necessarily be the case in other parts of the world. Moreover I would suggest that further research is required on the deployment of 'sustainability' within debates on farm animal breeding and new technologies in order to provide a better understanding of the extent to which they can make a real contribution to enhancing the environmental and social dimensions of agriculture. 
The intention in this section has been to explore some of the ways in which new molecular techniques in animal breeding are being contextualised by broader socioeconomic change. We are, it should be noted, still in the early days of such technologies, with only limited commercialisation of genomics and remaining doubts within significant areas of animal science communities over the ethics and technical viability of cloning and genetic modification. However, many possibilities are being pursued that would cast animals as significant actors within global relations of bioeconomic exchange. These span and intertwine the agricultural and medical domains including GM models, biopharmaceutical animals, persistent attempts to develop animals for xenotransplantation and selection for farm animals using both quantitative genetics and newer molecular techniques. Cloning is also being applied to companion animals, ${ }^{32}$ racing animals and in the hope of conserving threatened species. For much of the remainder of this paper I want to focus on the processes which are key to constructing animals as bioeconomic actors. This necessitates giving attention to the processes that do work upon animal bodies that convert them into newly mobile sources of value and exchange.

\section{Animals, biovalue and biopolitics}

Since they have for a very long time borne the imprint of human directedness, farm animals may be considered some of the first hybrid forms. But the new capacities for control, manipulation and possible redesign introduced by molecular techniques entails that this hybridity is intensified. Such work upon animal bodies takes place alongside human genomics. Research, whether it is centred on animal breeding or human disease, employs comparative work between databases of human and animal genomic information. The knowledge transfer now taking place echoes that which took place during the earlier part of the twentieth century between animal and human reproductive science. ${ }^{33}$ Yet a monolithic analysis that posits advancing trends of body rationalisation risks missing the differences that are taking place between the human and the animal, notably how human/animal relations and the moral value of nonhuman animal life are being constructed in the process. ${ }^{34}$ Animal biotechnology is potentially controversial given that it suggests various ways for extending the instrumentalisation of animals precisely at a time when the moral value of animals is being contested.

Here I want to outline how animal biotechnology contains commonalities and differences with the human case and so try and flesh out some specificity for thinking about the rationalisation of animal bodies. Many authors ${ }^{35}$ have attempted to theorise the rise to cultural prominence of genomics and have drawn upon Canguilhem's idea of the notion of biological life as informational code and Foucauldian theories of biopolitics. Some, notably Haraway and Thacker, ${ }^{36}$ have incorporated animals into their thinking but have not especially pursued the notion of biopolitics and 'life as information' in the animal case. Consequently this is what I shall do here. ${ }^{37}$

What is it then that is crucial to commodification processes around animal bodies? If we recap Cooper's idea of autopoiesis, "a self-engendering of life from life", ${ }^{38}$ we can augment this with Waldby's idea of "biovalue" which she refers to as: 
"the yield of vitality produced by the biotechnological reformulation of living processes. Biotechnology tries to gain traction in living processes, to induce them to increase or change their productivity along specified lines, intensify their self-producing and selfmaintaining capacities...biotechnology finds insertion points between living and nonliving systems where new and contingent forms of vitality can be created, capitalizing on life" 39

These are useful concepts for thinking about innovation in animal biotechnologies and one can see how they provide good definitions for some in particular, notably the use of animal bodies as 'machines' for the production of biopharmaceuticals. Biovalue is also created by freeing animal DNA from its original context and recombining it in a new site. Moreover biovalue is not inherent to biotechnology but should be applied to the year-on value creation we have seen in animal breeding using quantitative genetics to produce what animal scientists refer to as 'genetic progress'; the cumulative enhancement of the herd.

Some features of animal biotechnology are already potentially useful for the construction of biovalue in a globalising economy. If globalisation is partly about the compression of time and space as well as commodity standardisation then biotechnology introduces a novel malleability, narrowing distance between species and reorganising evolutionary time. If the aim of animal breeding has been to produce healthy high quality animals as products then cloning may potentially offer a new level of optimal standardisation. Although the debate on human cloning has been aired through concerns about individuality and concepts of dignity, a desocialised view of animals has contributed to the absence of a similar degree of ethical concern for cloned animals. Generally the significant difference between the cultural application of ethical frameworks related to human biotechnology vis-à-vis animal biotechnology means a more liberal licence for optimising biovalue in the animal case. Whilst scientific projects for enhancing reproduction extend across the human/animal dichotomy, what we do upon animal bodies continues in a manner to structure what is morally unacceptable in the human case. The closest we get to controlled breeding in the human case are technologies such as pre-implantation genetic diagnosis (PGD) or perhaps sex selection. ${ }^{40}$ Comprehensive human germline breeding remains at this point in time within the blue-skies deliberations of bioethicists.

In spite of these differences I do want to argue that biopolitics, so remarked upon in the human case by social scientists, are just as relevant in farm animal breeding. ${ }^{41}$ Indeed, due to different ethics the analysis works better. Although Foucault did not apply his theory of biopolitics to animals, in his discussion of pastorship as the mode of modern individualising power he does historicise biopower in terms of human/animal relations: "It isn't enough to know the state of the flock. That of each sheep must also be known". "Here he taps into Christian themes of shepherdry and providential care as important antecedents of biopower. Foucault's theory of biopower is of course understood as the management of human life and subjectivities through knowledge/discourse that broadly serve the economic and social regulation of modern rationalised societies. He defined it specifically as the "endeavour, begun in the 18th Century, to rationalize problems presented to governmental practice by the 
phenomena characteristic of a group of living humans beings constituted as a population: health, sanitation, birth rate, longevity, race". 33 This concept is then specified with two inter-related aspects, first an anatomopolitics of the body, "centred on the body as a machine: its disciplining, the optimization of its capabilities, the extortion of its forces, the parallel increase of its usefulness and its docility, its integration into systems of efficient and economic controls" and a biopolitics of the population, "focused on the species body, the body imbued with the mechanics of life and serving as the basis of the biological processes: propagation, births and mortality, the levels of health, life expectancy and longevity, with all the conditions that can cause these to vary" "44 I think there is a reading of Foucault that can make a strong argument for the agricultural animal as representing a biopolitical ideal type. But to begin with there are two ways in which this may not be the case. First, Foucault's point was that biopower supersedes sovereign power, but in the animal case sovereign power is obviously very much still operative, ${ }^{45}$ and, second, biopower is a technology that constructs subjectivity and it's unclear that we can talk about this in the animal case. ${ }^{46}$ Nevertheless, post-war animal science especially has exerted a considerable degree of biopower over agricultural animals for it is not merely that the animal body must be primed to be economically productive but that the body itself must work toward its own consumption. The 'genetic progress' made on animal bodies during this period together with increased availability and the decreased price of animal products also shows how this biopower was in a sense subservient to the overarching project of constructing healthy human bodies. ${ }^{47}$

Animal science has and continues to put much labour into both anatamopolitics and population biopolitics. Docility has been selected for across all agricultural species in that disruptive or aggressive animals will tend to be selected out. A whole array of animal science sub-disciplines work to ensure that animal bodies are disciplined to be at the optimum for production. These include but are not limited to meat science, behavioural science, reproductive science and a focus on feed efficiency, physiology, development, nutritional quality, immunity and disease, biometrics, environmental impact as well as methods of slaughter. The notion of 'genetic progress' could be taken as an annual measure of biopower success but genetics is only a part (although increasingly so) of animal biopolitics. Here optimization projects strike deeper due to the absence of human norms of privacy, autonomy ${ }^{48}$ and justice. Normatively dystopian fears about encroaching biopolitical management of society are informed by this legitimated animal shadow biopower. Thus ethical objections to new technologies on the grounds of human dignity not only encourage reflection on the 'human' but also upon the human/animal distinction by which it is partly constituted.

An important facet of both forms of biopower for the further production of biovalue is the genetic view of life as informational code. Animal genomics for example is in certain important ways an information science. This is evidenced by the material practices of animal scientists which involve less and less lab based work and more time in front of a computer screen doing work on database molecular information representations of animal bodies. Following earlier work by Canguilhem on the coming together of information theory and molecular biology ${ }^{49}$ several authors have analysed this as a part of emergent biopolitics. It is a vital process in the conversion of biology into biovalue. At this point it's worth quoting an interview extract from a 
discussion on transgenics. On the question of moving DNA from one species to another one scientist said:

\begin{abstract}
"If you think about it it boils down to the identity of that little piece of sequence. Now my personal view is that it's just a piece of DNA sequence. Whether it has, it could be isolated from, it could have a pig gene and you want to put it into a mouse lets say. You could go to a pig, you could take some blood, you could isolate some DNA from that blood, you could isolate that gene from a sheep and you could put it into the mouse. Or you could say I know that sequence, I'm going to go to a machine and I'll make that sequence and it's a pig sequence and I'll put it into a mouse. Now are they both pig genes? They're just a piece of DNA, to me its just a piece of DNA"
\end{abstract}

This raises interesting questions for genetic identity but for the purpose of this discussion it illustrates how DNA can come to be seen as mobile information largely detached from its original context. It is Thacker who has probably analysed this in most detail, writing on the movement of biological material from the 'wet' lab to become 'dry' information, a new media. He writes:
"Biological exchange, in conceiving of biology as information that exists - and persists - across media, radically widens the possibility of what can be exchanged within the biological domain. Not only is the biological commensurate with the economic (e.g., microbes, cells, or DNA that is patented or purchased for research), but the biological can be internally exchanged in ways that are not limited by the division between the material and the immaterial" ${ }^{50}$.

An example of this would be the transfer of DNA onto a chip which can then enter into relations of economic exchange as a biovaluable research tool. Although it is as if life as information code has gradually come to lose its metaphorical content, Thacker argues that the dematerialisation of biology can only go so far. Information is both immaterial and material, ${ }^{51}$ the former allowing for its entry into global relations of exchange and the latter ensuring either biovalue or promissory biovalue.

Another contributory process to the codification of DNA and biological abstraction is the generation of statistical data around genetic knowledge. In animal science this developed alongside quantitative genetics. Statistics are pressed into service in order to try and calculate the economic advantage of going for a particular genetic selection, and of combining particular genetic and environmental adjustments. If animals are converted, abstracted and valorised as economically relevant genes, markers and quantitative trait loci within their codification as DNA, then within associated statistical estimates they can be said to become elements within complex mathematical equations. For Foucault statistics were an important element of biopolitical management. ${ }^{52}$ In the animal context we can think of animal breeding as a highly controlled state of its own. One modelling technique in animal science is known as bioeconomic modelling. Indeed bioeconomic modelling techniques emerged in the 1980s within agricultural economics ${ }^{53}$ and provide an augmentation to Cooper's historicisation of the bioeconomy discussed earlier. Bioeconomic approaches are a convergence of animal genetics, economics and statistical modelling 
and are used across all agricultural species. ${ }^{54}$ The development of such techniques has been catalysed by the corresponding development of information technology. Best Linear Unbiased Prediction (BLUP) is a sophisticated statistical software program that geneticists use to estimate breeding values of animals. Moreover it aims to separate out genetic factors from environmental factors and so yield accurate knowledge of the value of selection alone. A focus on the productive performance of an animal inevitably constructs a partial view of the value of the animal. Holloway notes this surge in statistical modes of animal evaluation, arguing that they sit in tension with vernacular visual judgements of the animal by farmers which are now deemed to be scientifically unreliable. In an analysis that chimes with that of Thacker above, he states

"As data are made and studied, particular forms of knowledge of the
animal body are gained, but the totality of the animal is lost. There
is an iterative process of abstraction, as 'raw' data from related
animals are processed to construct individual's estimated breeding
values (EBV) for specific traits, generalised indices for beef or
calving values, and an index comparing animals with others of their
breed. Ultimately, an abstract, simplified yet comprehensible
representation of the complex reality of nature is put onto paper or
computer disks, forms which can then themselves be transported and
examined in places and times away from the sites of data
collection",55

Indeed 'nature' is constructed in such a way as to make it malleable and useful. The abstraction process opens up the possibility for human intervention and 'enhancement' of 'nature'.

A unifying theme running through many commentaries on biopolitical constructions of human embodiment is a concern with reductionism. Thus to what extent do, for example genetic databases, in their extraction of genetic knowledge put forward a desocialised view of the body? A common criticism of UK Biobank, the project to take sample DNA from 500,000 people, has been that it valorises a genetically determinist view of health. ${ }^{56}$ What may be seen as absent or insufficiently accounted for includes public health perspectives and a broader theorisation of the body as socially, politically and ecologically embedded. A similar tension between reductionism and complexity is played out in the context of farm animal breeding. However this takes place within a Cartesian historical context which has naturalised a biologically determinist view of animals. As Burke points out, it is often scientific research on animals that is then employed to project such determinism onto human behaviour. ${ }^{57}$ The tension between complexity and reductionism was also evident from respondents interviewed. This took two forms. First, it was clear that the challenge of genomics is considerable. Although genome sequencing is producing more 'information', it remains complex to actually discover the underlying gene/s involved in traits of interest. Gene interactions also complicate matters as does a renewed interest in epigenetics which may make it more difficult to predict animal performance. Second, it became obvious that the tension was evident in the differing conceptions of the animal between geneticists and welfare scientists. Unsurprisingly the latter want to put an emphasis on animal subjectivity and sociability which can clash and sit rather 
oddly with an overly genetic model of animal behaviour. One animal welfare scientist said in relation to genetic selection:
"Primarily my stance is that that whole paradigm is heavily reductionist obviously. So it is based on the purity reductionist approach to animals which and my problem with that is, you know it's not wrong but it's a huge imbalance. And a claim of the objective science paradigm that it's the only objective paradigm"

Thus sociologists who wish to re-socialise the human within genomic discourse have a shared concern with animal welfare scientists who wish to do the same with animals. But in the animal case it's arguably more of a challenge due to our tendency not to think of animals in terms of sociality and subjectivity, and because of the historical ideological investment of thinking about animals in this way. Our inheritance of dualistic modes of thinking about society and nature have entailed that in the distinctions of subject/object, mind/body, culture/nature, reason/emotion animals have tended to be associated with the second set of terms. ${ }^{58}$ As well as excluding 'animal' from 'human', this has been part of a modernist technology that has enabled many human groups to be associated with animality, a historically consistent and persistent mode of conceptualising human difference. Consequently attempts to start emphasising animal sociality and subjectivity have a considerable degree of discursive heritage to contend with. In addition what has been of specific use to biopower and is now reproduced in both medical human genomics and animal genomics is the mapping of the culture/nature distinction with that of mind/body. This underlying assumption of biopower appears to allow bodies of whatever species to be apprehended in an asocial manner which can then encourage an overestimation of the malleability of bodies. It is this decontextualisation move that is often behind the production of risk and in the case of animal breeding, surfaces in the unintended consequences of biopolitical control such as a narrowly productivist selection focus impacting welfare or the appearance of unexpected disease.

\section{Conclusion}

Although we can note differing 'animals' at play within animal genetics and animal welfare science it is clear that the former animal remains the dominant conception. The dominance of the biopolitically amenable animal is unsurprising given its interrelation with the commercial production of biovalue. The animal favoured within animal welfare science (and I would not want to suggest this is unitary or unanimous in either field of science) on the other hand represents both an economic cost and an ontological challenge. Therefore it is not surprising that many animal welfare scientists work pragmatically with geneticists in order to try and secure some change in the conditions of farm animals. It could be argued that by underemphasising animal sociality and subjectivity, animal genetics implicitly expresses overconfidence in knowledge of human/animal difference, a question that is fluid in various areas of scientific knowledge including genomics itself.

I have sought to analyse emergent technologies in animal breeding in terms of the interconnections between biopolitics, biovalue and the idea of the bioeconomy. 
Within these relations we find the ambivalence of contemporary human/animal relations in the form of contested truths about what an animal is and a broader struggle over the place of sustainability in future agricultures. ${ }^{59}$ Although I and others have alluded to the cultural tension between instrumentalism and subjectification at play within our human/animal relations, genomics itself amplifies this once more with its intimations of human/animal similarity and its intensification of the biopolitical interrogation of animal bodies. These relations would seem to fit Bauman's conception of postmodernity not as something that temporally supersedes modernity but as the instigation of ambivalence and uncertainty as defining themes of our times. ${ }^{60}$ This is a rather different account to the postmodern politics of difference alluded to at the outset but complimentary in the sense that for Bauman postmodernity is also a reflection upon ambivalence. It is then a political act to name the ambivalence and contradictions with which we treat animal others, as opposed to merely living with unaccounted incongruity.

Any counter narratives of progress wishing to explore new ethical dimensions of human/animal relations must encounter the usefulness that modernity has found for the symbolic category of the 'animal' in structuring difference and identity. Although it is itself uncertain how cultural tensions will shape animal biotechnologies and farm animal breeding generally, in the future it is likely that the increasingly global context in which these industries operate will lead to fragmented and diverse outcomes. As highlighted above, global population trends are also being used as an argument for a new productivism. ${ }^{61}$ The globalisation of animal production encourages more liberal regulation ${ }^{62}$ and could open up new spaces for the promotion of biotechnological innovation. If, as seems possible, the 'livestock revolution' becomes the stage on which we revisit a productivist focus upon animal breeding (potentially in tandem with new molecular technologies) then it will have to answer comprehensively the real challenge of environmental sustainability as well face ongoing alternative posthuman voices for animal ethics.

\section{Acknowledgements}

The support of the Economic and Social Research Council (ESRC) is gratefully acknowledged. The work was part of the programme of the ESRC Centre for Economic and Social Aspects of Genomics (CESAGen). I would also like to thank scientists and administrative staff working at the Roslin Institute and the Scottish Agricultural College for their co-operation and engagement with my work.

\footnotetext{
${ }^{1}$ ESRC Centre for Economic and Social Aspects of Genomics (CESAGen), Lancaster University, UK r.twine@lancaster.ac.uk

${ }^{2}$ K. Thomas. 1983. Man and the Natural World: A History of the Modern Sensibility. London: Routledge; A. Franklin. 1999. Animals and Modern Cultures : A Sociology of Human-Animal Relations in Modernity. London: Sage; P. Macnaghten. Animals in their nature: a case study of public attitudes on animals genetic modification and 'nature'. Sociology 2004; 38 (3): 533-551.

${ }^{3}$ At the time of writing (April 2007) the EU's European Food Safety Authority (EFSA) and the European Group on Ethics (EGE) as well as the US's Food and Drug Administration (FDA) are considering the subject of the human consumption of cloned farmed animals.
} 
${ }^{4}$ M. Michael. Technoscientific bespoking: animals, publics and the new genetics. New Genetics and Society 2001; 20 (3): 205-224.

${ }^{5}$ See MacNaghten, op. cit. note 2.

${ }^{6}$ R. Twine. Ma(r)king Essence: Ecofeminism and Embodiment. Ethics and the Environment 2001; 6 (2): 31-58.

${ }^{7}$ See A. Clarke. 1998. Disciplining Reproduction: Modernity, American Life Sciences, and the Problems of Sex. Berkeley: University of California Press.

${ }^{8} \mathrm{H}$. Tovey. Theorizing nature and society in sociology: The invisibility of animals. Sociologia Ruralis 2003; 43 (3): 196-215.

${ }^{9}$ Michael, op. cit. note 4.

${ }^{10} \mathrm{See}$ http://news.bbc.co.uk/1/hi/sci/tech/6431229.stm

${ }^{11}$ H. Buller \& C. Morris. Farm animal welfare: a new repertoire of nature-society relations or modernism re-embedded? Sociologia Ruralis 2003; 43 (3): 216-237, p.217.

${ }^{12}$ The idea of modernity being re-embedded in farm-animal farming is taken from Buller \& Morris, op. cit. note 11 .

${ }^{13}$ This statistic comes from Mintel, the consumer and market research group, as reported by the BBC here: http://news.bbc.co.uk/1/hi/uk/4551304.stm

${ }^{14}$ See W.M. Rauw et al. Undesirable side effects of selection for high production efficiency in farm animals: a review. Livestock Production Science 1998; 56; 15-33.

${ }^{15} \mathrm{Eg}$, E. Kanis et. al. Breeding for societally important traits in pigs. Journal of Animal Science 2005; 83: 948-957.

${ }^{16}$ I. Olesen et. al. Definition of animal breeding goals for sustainable production systems. Journal of Animal Science 2000; 78: 570-582. See also P. Thompson \& A. Nardone. Sustainable livestock production: methodological and ethical challenges. Livestock Production Science 1999; 61: 111-119.

${ }^{17}$ S. Bishop \& J. Woolliams. Genetic approaches and technologies for improving the sustainability of livestock production. Journal of the Science of Food and Agriculture 2004; 84: 911-919, p.911.

${ }^{18}$ I thank one of my referees for pointing out that interview responses here "could be treated as rhetoric, as less about the doing of animal genomics, and more about the talk that constructs/legitimates it in this given context". I think this is something to remain reflexive to. Here I would argue that there has been a limited change in animal science. It is of course germane to consider whether such changes get translated into agricultural practice.

${ }^{19}$ Bishop \& Woolliams, op. cit. note 17, p.913.

${ }^{20}$ This framing is evident in animal science discourse as well as in emergent company public relations in breeding companies such as Aviagen and Cherry Valley, for example.

${ }^{21}$ See V. Plumwood. 1993. Feminism and the Mastery of Nature London: Routledge.

${ }^{22}$ Europa-Bio http://www.europabio.org/ represents Europe's leading biotechnology companies. It has created its own Bioeconomy portal here - http://www.bio-economy.net/

${ }^{23}$ OECD. 2006. The Bioeconomy to 2030 - designing a policy agenda. Paris: OECD Publications: 1.

${ }^{24}$ M. Cooper. Life, Debt, Autopoiesis - Inventing the Bioeconomy. Distinktions - Journal of

Scandinavian Social Theory 2007; May (Special Bioeconomics Issue): 2.

${ }^{25}$ Ibid. p. 12

${ }^{26}$ I discuss this in more detail later.

${ }^{27}$ The web-site for this Technology Platform can be found here: http://www.fabretp.org/

${ }^{28}$ FABRE-TP. 2006. Sustainable Farm Animal Breeding and Reproduction - A Vision for 2025

Brussels: FABRE Technology Platform: 16.

${ }^{29}$ Ibid. p.9

${ }^{30}$ See FAO. 2006. Livestock's Long Shadow -Environmental Issues and Options. LEAD/FAO.

Available online at http://www.virtualcentre.org/en/library/key pub/longshad/A0701E00.pdf (last accessed 10 April 2007). To this one should also add deleterious human health impacts of overconsuming animal products.

${ }^{31}$ See http://www.fao.org/WAIRDOCS/LEAD/X6115E/x6115e03.htm

${ }^{32}$ The pet cloning company Genetic, Savings and Clone went out of business in late 2006.

${ }^{33}$ Clarke, op. cit. note 7.

${ }^{34}$ See M. Foucault. 2001. Power: The Essential Works, Vol.3. London: Allen Lane: 299; P. Rabinow. 1992. Artificiality and enlightenment: from sociobiology to biosociality. In Incorporations. J. Crary \& S. Kwinter, eds. New York: Zone: 234-53, p.237. 
${ }^{35}$ Eg. D. Haraway. 1997. Modest Witness@Second Millenium. FemaleMan Meets OncoMouse: Feminism and Technoscience. London: Routledge; N. Rose. The politics of life itself. Theory, Culture and Society 2001; 18 (6): 1-30; C. Waldby. 2000. The Visible Human Project - Informatic Bodies and Posthuman Medicine. London: Routledge; E. Thacker. 2005. The Global Genome - Biotechnology, Politics and Culture London: The MIT Press.

${ }^{36}$ Haraway, op. cit. note 35; Thacker, op. cit. note 35.

${ }^{37}$ An aspect of animal biopolitics which space prevents me from discussing here is animal biometrics. Biometrics are increasingly important in agriculture in order to try and prevent the spread of disease.

${ }^{38}$ Cooper, op. cit. note 24, p.9.

${ }^{39} \mathrm{C}$. Waldby. Stem cells, tissue cultures and the production of biovalue. Health: An Interdisciplinary Journal for the Social Study of Health 2002; 6 (3): 305-323, p.9.

${ }^{40}$ Only the former is legal in the UK. Some authors would certainly wish to construct a continuum here between these and contraception as well as assisted reproduction technologies (ARTs). But my point here is about technologies that make a qualitative modification to bred populations.

${ }^{41}$ Foucault has been drawn upon before by social scientists and humanities scholars interested in human/animal relations. Examples are C. Palmer. 2004. Madness and Animality in Michel Foucault's Madness and Civilization. In Animal Philosophy: Essential Readings in Continental Thought. M. Calarco \& P. Atterton, eds. Continuum International; D. Wadiwel. Cows and Sovereignty: Biopower and Animal Life. Borderlands 2002; 1 (2): 1-8; L. Holloway. Subjecting cows to robots: farming technologies and the making of animal subjects. Environment and Planning D: Society and Space (forthcoming). To quote Wadiwel (p.1): "That...nonhuman animals are not clearly eligible for consideration within a discussion of biopolitics is not due to any poverty in the potential scope of Foucault's term. Rather, the deficiency relates to the tradition of politics itself, at least in the West, which has, by and large, exempted the nonhuman animal from agency as a political being".

${ }^{42}$ Foucault, op. cit. note 34, p.309.

${ }^{43}$ Rabinow, P. ed. (2000) Ethics: Subjectivity and Truth (Essential Works of Michel Foucault). Harmondsworth: Penguin: 73.

${ }^{44}$ M. Foucault. 1990. The History of Sexuality: Care of the Self Vol.3. Harmondsworth: Penguin: 139.

${ }^{45}$ For a lengthy discussion on animals and sovereign power see Wadiwel, op. cit. note 41 . For Foucault's example of a society "which has generalised biopower in an absolute sense, but which has also generalized the sovereign right to kill", see M. Foucault. 2003. Society Must Be Defended Lectures at the College de France, 1975-1976. London: Penguin.: 259-60.

${ }^{46}$ For a fascinating discussion and possible refutation of this point see Holloway, op. cit. note 41 .

${ }^{47}$ The negative health impact of over-consuming animal products notwithstanding.

${ }^{48}$ Interestingly as Holloway (op. cit. note 41) points out, the introduction of robotic milking systems are predicated around allowing for cow autonomy.

${ }^{49}$ In F. Delaporte, ed. 1994. A Vital Rationalist - Selected Writings from Georges Canguilhem. New York: Zed Books: 316-7.

${ }^{50}$ Thacker, op. cit. note 35, p.10.

${ }^{51}$ Ibid. p. 21

${ }^{52}$ Foucault, op. cit. note 45, p.246; Thacker, op. cit. note 35, p.22.

${ }^{53}$ Statistical methods of determining the economic value of selection choices have a much longer history.

${ }^{54}$ Eg, T. Roughsedge, P.R. Amer \& G. Simm. A bio-economic model for the evaluation of breeds and mating systems in beef production enterprises. Animal Science 2003; 77: 403-416; J. Conington et al. A bioeconomic approach to derive economic values for pasture-based sheep genetic improvement programs. Journal of Animal Science 2004; 82: 1290-1304.

${ }^{55}$ L. Holloway. Aesthetics, genetics, and evaluating animal bodies: locating and displacing cattle on show and in figures. Environment and Planning D: Society and Space 2005; 23: 883-902, p.892.

${ }^{56}$ Eg, Genewatch. 2006. UK Biobank gets go-ahead: GeneWatch UK response. Press release. Available at http://www.genewatch.org/article.shtml?als[cid]=507674\&als[itemid]=541998 (Last accessed 10 April 2007.)

${ }^{57}$ L. Burke. 1994. Feminism, Animals and Science - The Naming of the Shrew. Buckingham: Open University Press: 106. 
${ }^{58}$ For critiques of dualism see literatures in feminist philosophy, feminist geography and ecofeminist theory. For example, in ecofeminism see Plumwood, op. cit. note 21; G. Gaard. Toward a Queer Ecofeminism, Hypatia 1997; 12 (1): 114-37; and Twine, op. cit. note 6.

${ }^{59}$ See T. Lang \& M. Heasman. 2004. Food Wars - The Global Battle for Mouths, Minds and Markets. London: Earthscan.

${ }^{60}$ Z. Bauman. 1991. Modernity and Ambivalence. Cambridge: Polity Press: 271-2.

${ }^{61}$ FABRE-TP, op. cit. note 28, p.12.

${ }^{62}$ Please refer to the recent UK Department for Environment, Food and Rural Affairs (DEFRA) response to the Farm Animal Welfare Council's (FAWC) call for a new body to assess new technologies in animal breeding. DEFRA's opinion was that regulation might stifle innovation and should be better dealt with at an EU level or by an international body: DEFRA. 2006. Government response to the FAWC report on the welfare implications of animal breeding and breeding technologies in commercial agriculture London: DEFRA: 5. 